\title{
Male age influences the strength of Cardinium-induced cytoplasmic incompatibility expression in the carmine spider mite Tetranychus cinnabarinus
}

\author{
Rong-Rong XIE, Li-Li ZHou, Zhen-Jun ZhaO and Xiao-Yue HonG* \\ Department of Entomology, Nanjing Agricultural University; Nanjing, Jiangsu 210095, China \\ (Received 5 March 2010; Accepted 22 April 2010)
}

\begin{abstract}
'Candidatus Cardinium', a recently described bacterium from the Bacteroidetes group, causes diverse reproductive alterations of its arthropod hosts, including cytoplasmic incompatibility (CI), parthenogenesis and feminization. We detected severe CI expression induced by Cardinium in the carmine spider mite Tetranychus cinnabarinus (Boisduval). CI was expressed as a reduction in egg hatchability and a male-biased sex ratio in crosses between uninfected females and infected males. To determine whether male age affects Cardinium-induced CI expression, uninfected females were crossed with infected virgin males at different ages. Cardinium density in males, as measured by quantitative PCR using the 16S rDNA gene, declined rapidly with increasing age. The CI level also declined rapidly with increasing age. Cardinium lost the ability to induce CI by day 12 , and the Cardinium density declined to $3.0 \times 10^{6}$ copies per ml. Cardinium density was positively correlated with the CI level, which is consistent with the bacterial density model of CI. Our results suggest that both male age and Cardinium density are key factors in Cardinium-induced CI expression in T. cinnabarinus, and a threshold level of Cardinium density may be required for induction of CI.
\end{abstract}

Key words: Cardinium; Tetranychus cinnabarinus (Boisduval); cytoplasmic incompatibility; bacteria density

\section{INTRODUCTION}

Vertically transmitted, intracellular bacteria that distort the sex ratio of their hosts to increase their frequency are widespread in arthropods (O'Neill et al., 1997; Duron et al., 2008; Hilgenboecker et al., 2008). The best known of these bacteria is Wolbachia in the alpha-Proteobacteria that infects at least $10^{6}$ insect species alone (Hilgenboecker et al., 2008). Wolbachia have been implicated in all types of reproductive manipulations discovered to date, including cytoplasmic incompatibility (CI) (Bourtzis et al., 1996), male killing (Hurst et al., 1999), induction of thelytokous parthenogenesis (Stouthamer et al., 1993), and feminization of genetic males (Rousset et al., 1992). CI is the most common effect of Wolbachia infection. It is observed in crosses between infected males with females that are either uninfected (unidirectional CI) or infected with a different incompatible symbiont strain (bidirectional CI). CI results from an inappropriate interaction between sperm and eggs, which leads to embryonic mortality in diploid species or to the production of male excess in haplodiploid species (Tram et al., 2003). The mechanisms of CI remain unclear.

CI was once thought to be a unique phenotype of Wolbachia. Cardinium, a recently described bacterium belonging to the Cytophaga-Flavobacterium-Bacteroides (CFB) lineage, was the second bacterial lineage discovered to induce CI in arthropods (Hunter et al., 2003). Cardinium has been shown to be involved in a growing number of sex ratio manipulations in arthropods. These diverse manipulations include parthenogenesis (ZchoriFein et al., 2001, 2004), feminization (Weeks et al., 2001), CI (Hunter et al., 2003) and increased fecundity in the predatory mite Metaseiulus occidentalis (Weeks and Stouthamer, 2004). Cardinium has so far been found only in $6-7 \%$ of arthropod species tested, and appears to be less widespread than Wolbachia (Weeks et al., 2003; Zchori-Fein

\footnotetext{
* To whom correspondence should be addressed at: E-mail: xyhong@njau.edu.cn
} DOI: $10.1303 /$ aez.2010.417 
and Perlman, 2004; Duron et al., 2008). So far, only three cases of Cardinium-induced CI have been found in the parasitoid wasp Encarsia pergandiella (Hunter et al., 2003), the spider mite Eotetranychus suginamensis (Gotoh et al., 2007a), and the sexual spider mite Bryobia sarothamni (Ros and Breeuwer, 2009).

The expression of the Wolbachia-induced CI phenotype is affected by several factors, including age of the host, temperature, bacteria or host genes and bacterial density (Clancy and Hoffman, 1998; Poinsot et al., 1998; Reynolds and Hoffmann, 2002; Sakamoto et al., 2005). Wolbachia-induced CI intensity has been shown to decline rapidly with male age in the fruit fly Drosophila melanogaster (Reynolds and Hoffmann, 2002). The effect of male age on Wolbachia-induced CI was also observed in the planthopper Laodelphax striatellus (Noda et al., 2001) and in singly infected Aedes albopictus (Kittayapong et al., 2002). The less severe CI found in aged males was associated with a lower Wolbachia density (Clark et al., 2003). In contrast, no male ageing effect has been found in the planthopper Sogatella furcifera (Noda et al., 2001) or mosquito Culex pipiens (Rasgon and Scott, 2003; Duron et al., 2007). The effect of male age on the strength of Cardinium-induced CI is unknown, and nothing is known about the variation of Cardinium density with male age.

The carmine spider mite, Tetranychus cinnabarinus (Boisduval) is abundant throughout China as well as worldwide. It is a polyphagous herbivore that attacks cotton, bean, cucumber, eggplant, pepper, tomato, cucurbits, papaya, passion fruit and many other crops. In this study, we examined (1) the effect of Cardinium on the reproduction of $T$. cinnabarinus, (2) the influence of male age on Cardinium-induced CI expression and (3) the relationship between Cardinium density and male age.

\section{MATERIALS AND METHODS}

Spider mites. The carmine spider mite $T$. cinnabarinus was collected from soybean [Glycine $\max$ (L.) Merr.] leaves in Zhenjiang, Jiangsu Province, east China in July 2007. A screening of 40 adult females for Cardinium and Wolbachia by PCR (see below) showed that 6 females were singly infected with Cardinium, while the others were doubly infected with Cardinium and
Wolbachia. The nucleotide sequence of the $16 \mathrm{~S}$ rDNA gene from Cardinium has been submitted to the GenBank database (GenBank number: GU731426). Mites were reared on a leaf of the common bean (Phaseolus vulgaris L.) placed on a water-saturated sponge mat in Petri dishes (dia. 9) at $25 \pm 1{ }^{\circ} \mathrm{C}, 60 \%$ r.h. and under L16D 8 conditions.

Preparation of infected and uninfected lines. In order to cross infected and uninfected individuals, $100 \%$ singly Cardinium-infected and 100\% symbiont-uninfected lines were prepared separately. One female from the teleiochrysalis stage was allowed to lay eggs without being crossed with males. The eggs were reared until adulthood (males). After the males had reached sexual maturity, they were backcrossed with the mother. After the cross, the female adults were transferred to new leaf discs and were allowed to lay eggs for 3-5 days. Females were each checked for Cardinium and Wolbachia infection by PCR amplification. The eggs were reared separately on new leaf discs depending on the infection status of the mother. The above process was continued for four generations until all members of the population were confirmed to be infected with Cardinium (a 100\% singly Cardinium-infected population was obtained).

The uninfected lines were established by treating lines singly infected with Cardinium with tetracycline. Small leaf discs (ca. $3 \mathrm{~cm}^{2}$ ) from the common bean were placed on a cotton bed soaked in tetracycline solution $(0.1 \%, \mathrm{w} / \mathrm{v})$ in Petri dishes ( $9 \mathrm{~cm}$ in diameter), and kept for $24 \mathrm{~h}$ before they were used for rearing the newly hatched larvae. Distilled water was added daily to keep the cotton beds wet. The cotton and the leaf discs were replaced every 4 days. Three generations later, mites were checked by PCR to confirm that the lines were free of Cardinium. For the third and following generations, a sample of 40 mites was taken from the population $(n>500)$ and checked by PCR to confirm that the lines were free of Cardinium. These lines were maintained in a mass-rearing environment without antibiotics for about four generations ( 2 months) before use, to avoid the potential side-effects of antibiotic treatment.

DNA extraction and PCR amplification. DNA was extracted by homogenizing a single female adult in a $25 \mathrm{ml}$ mixture of STE buffer $(100 \mathrm{~mm}$ $\mathrm{NaCl}, 10 \mathrm{~mm}$ Tris-HCl, $1 \mathrm{~mm}$ EDTA, $\mathrm{pH}$ 8.0) and proteinase $\mathrm{K}(10 \mathrm{mg} / \mathrm{ml}, 2 \mu \mathrm{l})$ in a $1.5 \mathrm{ml}$ Eppen- 
dorf tube. The mixture was incubated at $37^{\circ} \mathrm{C}$ for $30 \mathrm{~min}$ and then $95^{\circ} \mathrm{C}$ for $5 \mathrm{~min}$. The samples were centrifuged briefly, and used immediately for PCR reactions or stored at $-20^{\circ} \mathrm{C}$ for later use.

To check for Wolbachia and Cardinium infection, all PCR reactions were run in $25 \mu \mathrm{l}$ buffer using the TAKARA Taq kit (No. R001B; Takara Co., Ltd.): $16.3 \mu 1 \mathrm{H}_{2} \mathrm{O}, 2.5 \mu 110 \times$ buffer, $1.5 \mu \mathrm{l}$ of $2.5 \mathrm{~mm}$ dNTP, $1.5 \mu \mathrm{l}$ of $25 \mathrm{~mm} \mathrm{MgCl}_{2}, 0.2 \mu \mathrm{l}$ Taq ( $1 \mathrm{U}), 2 \mu \mathrm{l}$ sample and $1 \mu \mathrm{l}$ primers ( $20 \mathrm{pmol}$ each). The primers used for the detection of Cardinium were CLOf and CLOr1 (Weeks et al., 2003), which amplified ca. 450 bp of $16 \mathrm{~S}$ rDNA. Each PCR was run for one cycle at $94^{\circ} \mathrm{C}$ for $2 \mathrm{~min}, 35$ cycles at $94^{\circ} \mathrm{C}$ for $30 \mathrm{~s}, 57^{\circ} \mathrm{C}$ for $30 \mathrm{~s}, 72^{\circ} \mathrm{C}$ for $30 \mathrm{~s}$ and a final extension of $5 \mathrm{~min}$ at $72^{\circ} \mathrm{C}$. Wolbachia was detected by using wsp gene primers wsp- $81 \mathrm{~F}$ and wsp-691R (Zhou et al., 1998), which amplified a $599 \mathrm{bp}$ product. Reactions were cycled 35 times at $94^{\circ} \mathrm{C}$ for $30 \mathrm{~s}, 52^{\circ} \mathrm{C}$ for $45 \mathrm{~s}$ and $72^{\circ} \mathrm{C}$ for 1 min. Reagent negative and positive controls were included in the reactions. The PCR products were electrophoresed in a $1.0 \%$ agarose gel in TBE/EtBr for $40 \mathrm{~min}$ at $60 \mathrm{~mA}$, and then photographed on a UV transilluminator.

Tests for cytoplasmic incompatibility (CI). To determine the effects of Cardinium infection, we carried out cross experiments between infected and tetracycline-treated cured mites. Colonies infected with Cardinium were designated as 'Ic' and uninfected (antibiotic-cured) colonies were designated as ' $U$ '. Single females in the teleiochrysalis stage (the last developmental stage before adult emergence) were placed with a 1- to 3-day-old adult virgin male from either the same or a different culture on the same leaf disk. Males were discarded 2 days after the females reached adulthood. The mated females were allowed to oviposit for 5 days. The eggs on the leaf discs were checked daily to determine hatchability, survival rate in immature stages and the sex ratio (\% daughters).

To test the influence of male age on the Cardinium-induced CI expression, 0-day-old virgin uninfected females were crossed with 1-, 4-, 8- and 12-day-old infected virgin males. Below, age indicates the number of days after emergence (day $0=$ emergence). Control crosses with uninfected males and females were run concurrently for comparison.

Data were analyzed with one-way analysis of variance (ANOVA) and means were compared using the Tukey-HSD test (SPSS13.0, 2004). To normalize the data, log transformation was used for the number of eggs laid per female and an arcsine square root transformation was used for egg hatchability, survival rate and female ratio.

Cardinium density measurement. Quantitative PCR (Q-PCR) was performed using an ABI PRISM 7300 Sequence Detection System (Applied Biosystems) to estimate the numbers of Cardinium in $T$. cinnabarinus. In this study, $16 \mathrm{~S}$ rDNA gene was amplified for Cardinium quantification. SYBR green was used to monitor the amplification reaction. Primers were designed specifically to amplify the $133 \mathrm{bp}$ region of the Cardinium 16S rDNA gene (CLOF 5'-CCTGGGCTAGAATGTATTTTG$3^{\prime}$ and CLOR 5'-AAAGGGTTTCGCTCGTTATAG-3'). The $20 \mu 1$ reaction mixture consisted of 10 $\mu 12 \times$ SYBRq Premix Ex Taq (Applied Biosystems), $10 \mu \mathrm{M}$ of each primer, $50 \times \mathrm{ROX}$ Reference Dye and $2 \mu \mathrm{l}$ DNA template. The Q-PCR cycling conditions included 1 cycle $\left(10 \mathrm{~s} 95^{\circ} \mathrm{C}\right)$ followed by 40 cycles $\left(5 \mathrm{~s} 95^{\circ} \mathrm{C}, 31 \mathrm{~s} 60^{\circ} \mathrm{C}\right)$, and finally 1 cycle $\left(15 \mathrm{~s} 95^{\circ} \mathrm{C}, 1 \mathrm{~min} 60^{\circ} \mathrm{C}, 15 \mathrm{~s} 95^{\circ} \mathrm{C}\right)$. Six virgin males of 1-, 4-, 8- and 12-day-old were collected. DNA of single mites was extracted using the above method. Three replicates were run and averaged for each DNA sample. Negative controls were included in all amplification reactions. A series of DNA standards prepared from plasmid DNA was used and standard curves were plotted using a 10 -fold dilution series from $10^{-8}$ to $10^{-4}$ copies numbers. The quality and concentration of all purified standard DNA are measured by OD absorbance at $260 \mathrm{~nm}$. The number of molecules in all samples is determined from the threshold cycles in the PCR based on a standard curve. Statistical analysis was performed using the Mann-Whitney $U$-test.

\section{RESULTS}

\section{Cytoplasmic incompatibility}

Crosses of artificial $U$ and Ic populations of the Zhejiang population of $T$. cinnabarinus showed that Cardinium is capable of causing strong CI (Table 1). In the cross between uninfected females and 1- to 3-day-old infected males (U/Ic), only $29.58 \%$ of all eggs hatched, against $95.65-97.88 \%$ in the other three crosses. Because of the large numbers of aborted eggs, the female ratio was also 
Table 1. Compatibility of crosses between Cardinium-infected (Ic) and antibiotic-treated (U) colonies in the Zhenjiang population of $T$. cinnabarinus

\begin{tabular}{lccccccc}
\hline $\begin{array}{l}\text { Cross } \\
\text { Female } \times \text { Male }\end{array}$ & $n^{\mathrm{a}}$ & $\begin{array}{c}\text { No. of } \\
\text { eggs/ } \\
\text { Female }\end{array}$ & $\begin{array}{c}\text { Hatchability } \\
(\%)\end{array}$ & $\begin{array}{c}\text { Survival rate in } \\
\text { immature stage } \\
(\%)\end{array}$ & $\begin{array}{c}\text { Female } \\
\text { offspring } \\
(\%)\end{array}$ & $\begin{array}{c}\text { No. of } \\
\text { F1 } \\
\text { females }\end{array}$ & $\begin{array}{c}\text { No. of } \\
\text { F1 } \\
\text { males }\end{array}$ \\
\hline $\mathrm{U} \times \mathrm{U}$ & 32 & $24.94 \pm 1.27 \mathrm{a}$ & $96.53 \pm 0.57 \mathrm{~b}$ & $93.61 \pm 1.37 \mathrm{~b}$ & $83.86 \pm 0.79 \mathrm{~b}$ & $18.91 \pm 1.06 \mathrm{~b}$ & $3.59 \pm 0.25$ \\
$\mathrm{U} \times \mathrm{Ic}$ & 20 & $26.25 \pm 1.84 \mathrm{a}$ & $29.58 \pm 2.73 \mathrm{a}$ & $84.74 \pm 2.85 \mathrm{a}$ & $48.75 \pm 7.31 \mathrm{a}$ & $3.85 \pm 0.84 \mathrm{a}$ & $2.90 \pm 0.40$ \\
$\mathrm{Ic} \times \mathrm{U}$ & 31 & $33.90 \pm 0.66 \mathrm{~b}$ & $97.88 \pm 0.51 \mathrm{~b}$ & $96.00 \pm 0.65 \mathrm{~b}$ & $87.20 \pm 0.71 \mathrm{~b}$ & $27.77 \pm 0.62 \mathrm{c}$ & $4.06 \pm 0.24$ \\
$\mathrm{Ic} \times \mathrm{Ic}$ & 28 & $24.86 \pm 0.96 \mathrm{a}$ & $95.65 \pm 0.74 \mathrm{~b}$ & $91.64 \pm 1.61 \mathrm{ab}$ & $84.15 \pm 1.02 \mathrm{~b}$ & $18.18 \pm 0.72 \mathrm{~b}$ & $3.46 \pm 0.26$ \\
$\mathrm{~F}_{3,107}$ & & $14.276^{* * *}$ & $282.805^{* * *}$ & $3.679 *$ & $30.529 * * *$ & $117.167 * * *$ & $2.593 \mathrm{NS}$ \\
\hline
\end{tabular}

${ }^{a}$ Number of pairs tested.

${ }^{\mathrm{b}}$ Means ( $\pm \mathrm{SE}$ ) differ significantly at $p<0.05(*), p<0.01(* *)$ and $p<0.001(* * *)$ (ANOVA); NS, not significant at the 5\% level. Values in a column followed by different letters are significantly different at $p<0.05$ (Tukey HSD test). The number of eggs per female, number of F1 females and number of F1 males were ln-transformed, and hatchability, survival rate and female ratio were arcsine-root transformed before ANOVA.

Table 2. Compatibility of crosses between uninfected females (U) and 1-, 4-, 8- and 12-day-old Cardinium-infected (Ic) or uninfected males in the Zhenjiang population of T. cinnabarinus

\begin{tabular}{ccccccccc}
\hline Cross & Male age & $n^{\mathrm{a}}$ & $\begin{array}{c}\text { No. of } \\
\text { eggs/ } \\
\text { Female }\end{array}$ & $\begin{array}{c}\text { Hatchability } \\
(\%)\end{array}$ & $\begin{array}{c}\text { Survival rate in } \\
\text { immature stage } \\
(\%)\end{array}$ & $\begin{array}{c}\text { Female } \\
\text { offspring } \\
(\%)\end{array}$ & $\begin{array}{c}\text { No. of } \\
\text { F1 } \\
\text { females }\end{array}$ & $\begin{array}{c}\text { No. of } \\
\text { F1 } \\
\text { males }\end{array}$ \\
\hline $\mathrm{U} \times \mathrm{Ic}$ & $1 \mathrm{~d}$ & 32 & $24.53 \pm 0.93 \mathrm{~b}$ & $16.33 \pm 1.29 \mathrm{a}$ & $89.48 \pm 3.31$ & $5.61 \pm 2.07 \mathrm{a}$ & $0.25 \pm 0.09 \mathrm{a}$ & $3.28 \pm 0.29 \mathrm{abc}$ \\
& $4 \mathrm{~d}$ & 20 & $23.05 \pm 1.12 \mathrm{ab}$ & $27.87 \pm 3.67 \mathrm{~b}$ & $90.20 \pm 3.42$ & $41.02 \pm 5.79 \mathrm{~b}$ & $2.70 \pm 0.60 \mathrm{a}$ & $2.85 \pm 0.31 \mathrm{ab}$ \\
& $8 \mathrm{~d}$ & 30 & $19.17 \pm 0.82 \mathrm{a}$ & $76.80 \pm 4.13 \mathrm{c}$ & $97.19 \pm 1.06$ & $81.89 \pm 2.57 \mathrm{c}$ & $12.27 \pm 0.96 \mathrm{~b}$ & $2.27 \pm 0.26 \mathrm{a}$ \\
$\mathrm{U} \times \mathrm{U}$ & $12 \mathrm{~d}$ & 21 & $30.24 \pm 1.26 \mathrm{c}$ & $91.35 \pm 1.56 \mathrm{~d}$ & $96.43 \pm 0.87$ & $86.70 \pm 0.75 \mathrm{c}$ & $23.00 \pm 1.08 \mathrm{de}$ & $3.57 \pm 0.21 \mathrm{bc}$ \\
& $1 \mathrm{~d}$ & 26 & $33.19 \pm 0.86 \mathrm{c}$ & $96.58 \pm 0.70 \mathrm{~d}$ & $96.56 \pm 0.66$ & $84.30 \pm 0.84 \mathrm{c}$ & $26.00 \pm 2.62 \mathrm{e}$ & $4.88 \pm 0.32 \mathrm{~d}$ \\
& $4 \mathrm{~d}$ & 35 & $24.43 \pm 0.65 \mathrm{~b}$ & $95.35 \pm 1.02 \mathrm{~d}$ & $94.17 \pm 0.53$ & $85.33 \pm 0.82 \mathrm{c}$ & $18.80 \pm 0.67 \mathrm{c}$ & $3.17 \pm 0.19 \mathrm{abc}$ \\
& $8 \mathrm{~d}$ & 33 & $30.45 \pm 1.09 \mathrm{c}$ & $94.48 \pm 1.28 \mathrm{~d}$ & $94.65 \pm 0.66$ & $84.07 \pm 0.63 \mathrm{c}$ & $22.76 \pm 0.76 \mathrm{~d}$ & $4.27 \pm 0.20 \mathrm{~cd}$ \\
& $12 \mathrm{~d}$ & 25 & $21.36 \pm 0.98 \mathrm{ab}$ & $94.38 \pm 1.08 \mathrm{~d}$ & $96.27 \pm 0.83$ & $85.57 \pm 0.92 \mathrm{c}$ & $16.56 \pm 0.77 \mathrm{c}$ & $2.84 \pm 0.24 \mathrm{ab}$ \\
& $\mathrm{F}_{7,214} \mathrm{~b}$ & & $26.292 * * *$ & $240.052 * * *$ & $2.801 \mathrm{NS}$ & $225.070 * * *$ & $166.112 * * *$ & $11.096 * * *$ \\
\hline
\end{tabular}

\footnotetext{
${ }^{a}$ Number of pairs tested. sine-root transformed before ANOVA.

significantly lower in the predicted incompatibility crosses than in the other crosses. This was due to a decrease in the number of females produced, as the number of males produced was not significantly different among the four crosses.
}

${ }^{\mathrm{b}}$ Means ( \pm SE) differ significantly at $p<0.01(* *)$ and $p<0.001(* * *)$ (ANOVA); NS, not significant at the $5 \%$ level. Values in a column followed by different letters are significantly different at $p<0.05$ (Tukey HSD test). The number of eggs per female, number of F1 females and number of F1 males were ln-transformed, and hatchability, survival rate and female ratio were arc-

\section{Effect of male age on CI expression}

Following the finding of a high level of Cardinium-induced $\mathrm{CI}$ in $T$. cinnabarinus, we tested the effects of male age on CI expression. In the cross between uninfected females and 1-day-old infected males (U/Ic), only $16.33 \%$ of all eggs hatched compared to $96.58 \%$ in the control cross between uninfected females and 1-day-old unin- fected males (U/U) (Table 2). Twenty-five pairs of cross U/Ic produced no F1 females, while the other seven pairs produced one or two F1 females per pair, indicating a severe CI effect by Cardinium. The high CI induced by 1-day-old males declined rapidly with increasing male age. Twelve-dayold males expressed no CI. No differences were observed in the hatchability of eggs $(p>0.05$, Tukey HSD test) or female ratio ( $p>0.05$, Tukey HSD test) between the incompatible cross (U/Ic) and the control cross $(\mathrm{U} / \mathrm{U})$ when males were 12 days old (Table 2). 


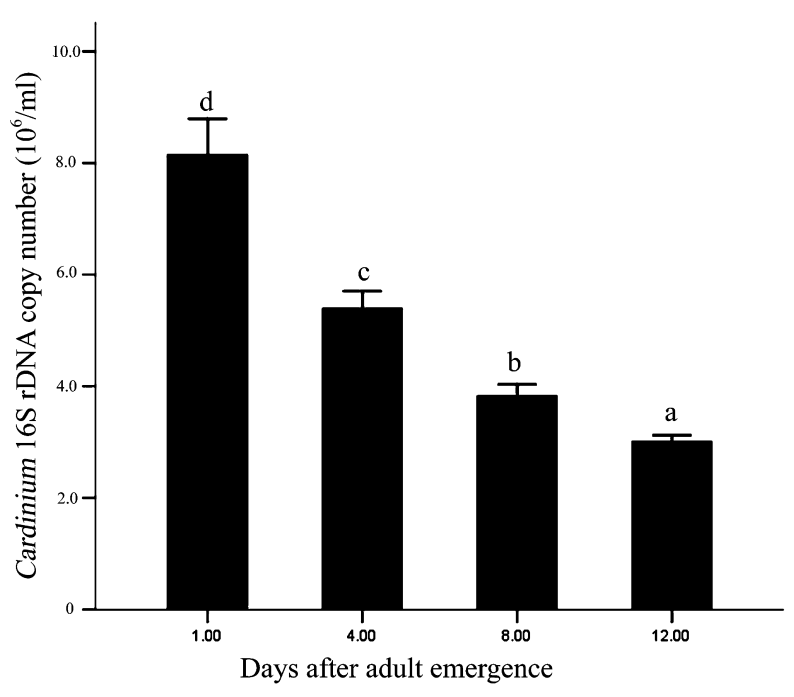

Fig. 1. Cardinium density during male aging in the Zhenjiang population of $T$. cinnabarinus. Copy number of Cardinium per $\mathrm{ml}$ was determined by quantitative PCR using the $16 \mathrm{~S}$ rDNA gene. Each point is the average of three measurements of six samples. Bars indicate standard errors. a, b, c and $\mathrm{d}$ represent statistic groups (Mann-Whitney $U$-test, $p<0.05$ ).

\section{Cardinium density measurement}

To find out whether there was a link between the copy numbers of Cardinium and male age, we measured the densities of Cardinium in males at different ages. Cardinium density declined rapidly with increasing age, ranging from $8.1 \times 10^{6} \pm 0.7 \times 10^{6}$ to $3.0 \times 10^{6} \pm 0.1 \times 10^{6}$ copies per ml (Fig. 1). MannWhitney tests indicated that the difference between every two ages was significant $(p<0.05)$. To our knowledge, this is the first report of the copy number of Cardinium in a spider mite.

\section{DISCUSSION}

We found strong evidence that Cardinium induced severe CI in T. cinnabarinus. CI was expressed as a reduction in egg hatchability and a male-biased sex ratio in crosses between uninfected females and infected males. This is concordant with the female mortality type of CI (Vavre et al., 2000). In contrast, no Cardinium-induced CI expression was found in three populations of Tetranychus urticae (Koch) (red form) in Japan (Gotoh et al., 2007a). The red form of T. urticae is called T. cinnabarinus in China. The CI-inducing Cardinium strain infecting $T$. cinnabarinus and the non-CI-inducing strain in the B (AB241133) and C (AB241134) group of T. urticae (red form) had almost the same
16S rDNA sequence (only $1 \mathrm{bp}$ difference out of $1,338 \mathrm{bp}$ ). A similar phenomenon was found in Wolbachia strains in T. urticae (Gotoh et al., 2003, 2007b). Expression of the Wolbachia-induced CI phenotype is affected by the bacterial strain (or bacteria gene), host age, temperature, host genes and bacterial density. Cardinium-induced CI expression may also be affected by these factors.

Our findings that Cardinium-induced CI declined rapidly with increasing male age (Table 2) emphasizes the need to take male age into account before it can be concluded that strains are true nonCI expressers. CI expression might be variable in the field due to the presence of both young and old males, which would slow down the spread of Cardinium infection to some extent. In Wolbachiainfected hosts, CI was weaker with old males of the fruit fly D. melanogaster (Reynolds and Hoffmann, 2002), planthopper L. striatellus (Noda et al., 2001) and singly infected mosquito A. albopictus (Kittayapong et al., 2002). Reduction in Wolbachiainduced CI strength with male age is associated with the loss of symbionts in developing sperm cysts with advancing male age (Noda et al., 2001; Clark et al., 2003). It appears that Wolbachia multiplication does not match the production rate of new spermatocytes and that, as a result, Wolbachia becomes diluted. At decreased density, Wolbachia presumably does not modify the sperm. Hence, it is possible that the observed effect of male age on Cardinium-induced CI could be explained by the relationship between male age and Cardinium density.

Our findings that Cardinium density declined rapidly with increasing male age (Table 2), as did Cardinium-induced CI, are consistent with the finding of positive relationships between Wolbachia density and CI strength (Breeuwer and Werren, 1993; Noda et al., 2001; Clark et al., 2003; Bordenstein et al., 2006). Together, these results support the bacterial density model of CI. We suggest that Cardinium density is a factor critical for CI intensity in the Zhenjiang population of $T$. cinnabarinus, and a threshold level of Cardinium density may be required for the induction of CI.

\section{ACKNOWLEDGMENTS}

We are grateful to Xiao-Lin Chen, Ming-Hong Lu and Dong-Xiao Zhao for their kind help with experiments. This study was supported in part by a Grant-in-aid from the 
National Basic Science Program of China (973 Program, No. 2006CB102001; No. 2009CB119202), a Grant-in-aid from the Science and Technology Research Program of the National Public Welfare Fund (nyhyzx-07-057) from the Ministry of Agriculture of China, and a Grant-in-Aid for Scientific Research (No. 30871635) from the National Natural Science Foundation of China.

\section{REFERENCES}

Bordenstein, S. R., M. L. Marshall, A. J. Fry, U. Kim and J. J. Wemegreen (2006) The tripartite associations between bacteriophage, Wolbachia, and arthropods. PLoS Pathog. 2: e43.

Bourtzis, K., A. Nirgianaki, G. Markakis and C. Savakis (1996) Wolbachia infection and cytoplasmic incompatibility in Drosophila species. Genetics 144: 1063-1073.

Breeuwer, J. A. J. and J. H. Werren (1993) Cytoplasmic incompatibility and bacterial density in Nasonia vitripennis. Genetics 135: 565-574.

Clancy, D. J. and A. A. Hoffmann (1998) Environmental effects on cytoplasmic incompatibility and bacterial load in Wolbachia-infected Drosophila simulans. Entomol. Exp. Appl. 86: 13-24.

Clark, M. E., Z. Veneti, K. Bourtzis and T. L. Karr (2003) Wolbachia distribution and cytoplasmic incompatibility during sperm development: the cyst as the basic cellular unit of CI expression. Mech. Dev. 120: 185-198.

Duron, O., P. Fort and M. Weill (2007) Influence of age on cytoplasmic incompatibility, sperm modification and Wolbachia density in Culex pipiens mosquitos. Heredity 98: 368-374.

Duron, O., G. D. D. Hurst, E. A. Hornett, J. A. Josling and J. Engelstadter (2008) High incidence of the maternally inherited bacterium Cardinium in spiders. Mol. Ecol. 17: $1427-1437$.

Gotoh, T., H. Noda and X. Y. Hong (2003) Wolbachia distribution and cytoplasmic incompatibility based on a survey of 42 spider mite species (Acari: Tetranychidae) in Japan. Heredity 91: 208-216.

Gotoh, T., H. Noda and S. Ito (2007a) Cardinium symbionts cause cytoplasmic incompatibility in spider mites. Heredity 98: 13-20.

Gotoh, T., J. Sugasawa, H. Noda and Y. Kitashima (2007b) Wolbachia induced cytoplasmic incompatibility in Japanese populations of Tetranychus urticae (Acari: Tetranychidae). Exp. Appl. Acarol. 42: 1-16.

Hilgenboecker, K., P. Hammerstein, P. Schlattmann, A. Telschow and J. H. Werren (2008) How many species are infected with Wolbachia?-A statistical analysis of current data. FEMS Microbiol. Lett. 281: 215-220.

Hunter, M. S., S. J. Perlman and S. E. Kelly (2003) A Bacteroidetes-group bacterial symbiont induces cytoplasmic incompatibility in the parasitoid wasp Encarsia pergandiella. Proc. R. Soc. Lond. B 270: 2185-2190.

Hurst, G. D. D., F. M. Jiggins, J. H. G. Van der Schulenburg, D. Bertrand, S. A. West, I. I. Goriacheva, I. A. Zakharov, J. H. Werren, R. Stouthamer and M. E. N. Majerus (1999) Male-killing Wolbachia in two species of insect. Proc. R. Soc. Lond. B 266: 735-740.
Kittayapong, P., P. Mongkalangoon, V. Bamai and S. L. O'Neill (2002) Host age effect and expression of cytoplasmic incompatibility in field populations of Wolbachia-superinfected Aedes albopictus. Heredity 88: 270-274.

Noda, H., Y. Koizumi, Q. Zhang and K. Deng (2001) Infection density of Wolbachia and incompatibility level in two planthopper species, Laodelphax striatellus and Sogatella furcifera. Insect Biochem. Mol. Biol. 31: 727-737.

O’Neill, S. L., A. A. Hoffmann and J. H. Werren (eds.) (1997) Influential Passengers: Inherited Microorganisms and Arthropod Reproduction. Oxford University Press, New York. 214 pp.

Poinsot, D., K. Bourtzis, G. Markakis, C. Savakis and H. Merçot (1998) Wolbachia transfer from Drosophila melanogaster into D. simulans: host effect and cytoplasmic incompatibility relationships. Genetics 150: 227237.

Rasgon, J. L. and T. W. Scott (2003) Wolbachia and cytoplasmic incompatibility in the California Culex pipiens mosquito species complex: parameter estimates and infection dynamics in natural populations. Genetics 165: 20292038.

Reynolds, K. T. and A. A. Hoffmann (2002) Male age, host effects and the weak expression or non-expression of cytoplasmic incompatibility in Drosophila strains infected by maternally transmitted Wolbachia. Genet. Res. 80: 79-87.

Ros, V. I. D. and J. A. J. Breeuwer (2009) The effects of, and interactions between, Cardinium and Wolbachia in the doubly infected spider mite Bryobia sarothamni. Heredity 102: 413-422.

Rousset, F., D. Bouchon, B. Pintureau, P. Juchault and M. Solignac (1992) Wolbachia endosymbionts responsible for various alterations of sexuality in arthropods. Proc. $R$. Soc. Lond. B 250: 91-98.

Sakamoto, H., Y. Ishikawa, T. Sasaki, S. Kikuyama, S. Tatsuki and S. Hoshizaki (2005) Transinfection reveals the crucial importance of Wolbachia genotypes in determining the type of reproductive alteration in the host. Genet. Res. 85: 205-210.

SPSS Inc. (2004) SPSS 13.0 for Windows from http://www. spss/com

Stouthamer, R., J. A. J. Breeuwer, R. F. Luck and J. H. Werren (1993) Molecular identification of microorganisms associated with parthenogenesis. Nature 361: 66-68.

Tram, U., P. M. Ferree and W. Sullivan (2003) Identification of Wolbachia-host interacting factors through cytological analysis. Microbes Infect. 5: 999-1011.

Vavre, F., F. Fleury, J. Varaldi, P. Fouillet and M. Boulétreau (2000) Evidence for female mortality in Wolbachiamediated cytoplasmic incompatibility in haplodiploid insects: epidemiologic and evolutionary consequences. Evolution 54: 191-200.

Weeks, A. R. and R. Stouthamer (2004) Increased fecundity associated with infection by a Cytophaga-like intracellular bacterium in the predatory mite, Metaseiulus occidentalis. Proc. R. Soc. Lond. B (Suppl.) 271: S193-S195.

Weeks, A. R., F. Marec and J. A. J. Breeuwer (2001) A mite 
species that consists entirely of haploid females. Science 292: 2479-2482.

Weeks, A. R., R. Velten and R. Stouthamer (2003) Incidence of a new sex-ratio-distorting endosymbiotic bacterium among arthropods. Proc. R. Soc. Lond. B. 270: 18571865.

Zchori-Fein, E. and S. J. Perlman (2004) Distribution of the bacterial symbiont Cardinium in arthropods. Mol. Ecol. 13: 2009-2016.

Zchori-Fein, E., Y. Gottlieb, S. E. Kelly, J. K. Brown, J. M. Wilson, T. L. Karr and M. S. Hunter (2001) A newly discovered bacterium associated with parthenogenesis and a change in host selection behavior in parasitoid wasps. P. Natl. Acad. Sci. USA 98: 12555-12560.

Zchori-Fein, E., S. J. Perlman, S. E. Kelly, N. Katzir and M. S. Hunter (2004) Characterization of a Bacteroidetes symbiont in Encarsia wasps (Hymenoptera: Aphelinidae): proposal of 'Candidatus cardinium hertigii'. Int. J. Syst. Evol. Micr. 54: 961-968.

Zhou, W. G., F. Rousset and S. L. O’Neill (1998) Phylogeny and PCR-based classification of Wolbachia strains using wsp gene sequences. Proc. R. Soc. Lond. B 265: 509515. 